УДК 82.09

ББК 83.3 (4 Фр.)
СПЕЦИФИКА ХУДОЖЕСТВЕННОГО

ПРОСТРАНСТВА

В РОМАНАХ КРЕБИЙОНА

(C) 2017 г. Н.Т. Пахсарьян

Московский государственный университет

им. М.В. Ломоносова, Москва, Россия

Дата поступления статьи: 30 января 2017 г.

Дата публикации: 25 марта 2017 г.

DOI: IO.22455/2500-4247-20I7-2-I-76-89

Аннотация: Интерес современной теории и истории литературы к проблеме художественного пространства, в частности, к романному пространству XVIII в., демонстрирует не только достижения в исследовании этой проблемы, но и лакуны. Так, достаточно точно выявлены процессы интимизации и феминизации романного пространства в романах рококо, установлены - в частности, в романах Кребийона-сына «Танзай и Неадарне», «Софа», «Заблуждения сердца и ума» - основные единицы пространства, однако внутрироманные пространственные отношения изучены недостаточно полно. Сопоставление внутрироманной топографии в «Астрее» О. д’Юрфе, «Принцессе Клевской» М.М. де Лафайет и в романах Кребийона позволяет сделать вывод, что риторическая театральность пространства барокко и классицизма заменяется в романах рококо детеатрализацией и топографической абстрактностью. Чисто вербальный, игровой вуайеризм кребийоновских романов не совпадает и с топографической наглядностью поз и жестов, описанных в фривольно-эротических сочинениях этой эпохи, например, в романе «Тереза-философ». Трансформация риторических пространственных топосов барочно-классицистической эпохи происходит у Кребийона, как и других авторов рокайльных романов, путем натурализации и психологизации романического.

Ключевые слова: художественное пространство, барокко, классицизм, рококо, романическое, интимизация, натурализация, психологизация.

Информация об авторе: Наталья Тиграновна Пахсарьян - доктор филологических наук, профессор, Московский государственный университет им. М.В. Ломоносова, Ленинские горы, ГСП-І, ІІ999г, Москва, г-й ГУМ, филологический факультет, ком. 970.

E-mail: natapa@mail.ru 


\section{THE SPECIFICITY OF THE FICTIONAL SPACE IN THE NOVELS \\ BY CRÉBILLON-FILS}

This is an open access article distributed under the Creative Commons Attribution 4.0 International (CC BY 4.0)
(C) 20I7. N.T. Pakhsarian

Lomonosov Moscow State University, Moscow, Russia

Received: January 30, 2017

Date of publication: March 25, 2017

Abstract: The interest of contemporary literary theory and literary history in the problem of fictional space and in the space in the $18^{\text {th }}$ century novels in particular reveals both achievements and gaps in this field. The latest studies have shed light on the intimization and feminization of the fictional space in rococo novels and have defined the spatial units in such novels by Crébillon-fils as L'Écumoire ou Tanzaï et Néadarné, Le Sopha, and Les Égarements du cœur et de l'esprit. However, the inner-novel spatial relationships have been generally neglected. Juxtaposition of the topography of such novels as L'Astrée by Honoré d'Urfé, La Princesse de Clèves by Madame de La Fayette, and the novels by Crébillon-fils demonstrates that rhetorical theatricality of the baroque and classicist space had been replaced in these works by de-theatralization and topographical abstraction of rococo novels. Purely verbal, playful voyeurism of the novels by Crébillonfils does not match with topographical precision of pose and gesture as described in the frivolous erotic writings of the period (as, for example in "Thérèse-philosophe"). Transformation of rhetorical spatial topoi of the baroque and classicist periods occurs in the works of Crébillon-fils, as it does in the works of other authors of rocaille novels, through naturalizing and psychologizing the novel's generic features.

Keywords: fictional space, baroque, classicism, rococo, generic features of the novel, intimacy, naturalization, psychologizing.

Information about the author: Natalia T. Pakhsarian, DSc in Philology, Professor, M.V. Lomonosov Moscow State University, Leninskie Gory, GSP-I, II999I Moscow, Humanities Building.

E-mail: natapa@mail.ru 
В последние десятилетия пространству и пространственности в литературе, особенно современной, посвящено довольно много исследований $[2 ; 4 ; 8 ; 9 ;$ II]. При этом художественное пространство сегодня понимают как предельно широко («Художественное пространство - это свойственная произведению искусства глубинная связь его содержательных частей, придающая произведению особое внутреннее единство и способствующая превращению его в эстетическое явление» [I]), так и более конкретно как «модель мира данного автора, выраженная на языке пространственных представлений» [6, с. 406]. Термину часто придается то метафорическое, то буквальное значение, его используют при анализе различных уровней поэтики произведения, говоря о сюжетном, нарративном, фабульно-событийном, персонажном, жанровом (трагедийное, комедийное, романное) пространствах.

Среди других видов художественного пространства романное изучается в последние десятилетия весьма активно, и роман XVIII в. играет в этих исследованиях особенно заметную роль: достаточно вспомнить монографии Ж. Вайсгербера [28], А. Лафона [2I], сборники работ под редакцией Ж. Бехтольда [I7], Н. Ферран [23], статьи А. Зимека [31], Х.Р. Хименеса Сальседо [г] и др.

Не останавливаясь подробно на обзоре этих исследований, выделю основные идеи, которые в них содержатся. Это, прежде всего, исследование своеобразия нарративного пространства романа от первого лица, полемика с представлением о «реалистичности» изображаемого мира в романах (одна из весомых публикаций, касающихся поэтики Кребийона-сына, не случайно называется «Сон, иллюзия, заблуждение в романах Кребийона» [26]) и одно- 
временно - указание на важность и силу риторической традиции в изображении пространства. Это также анализ феминизации пространства в романистике XVIII столетия [24], выделение топосов - уединения, соблазнения, связанных с интимным пространством салонов, будуаров, кабинетов, спален и т. п. По верному наблюдению А. Лафона, «комната ли, сад ли - функция одинакова - изолировать, уединить» [2I, с. I5]. В «укромный уголок» может быть превращено и публичное пространство: так, зал Оперы редуцируется до изображения ложи, в которой собственно и происходит действие; дорожное путешествие описано в романе В. Денона как пребывание в карете, и даже попытка выглянуть из окна оказывается лишь предлогом для

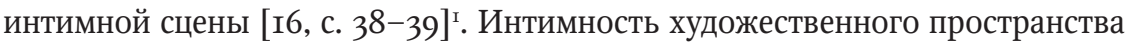
отвечала жизненно-бытовым реалиям эпохи, фиксировала те изменения, которые происходили не только в сознании современников, но в их повседневном укладе. О. Ижлен-Фюсте верно указывает на трансформации, происходящие, в частности, в принципах архитектурного строительства XVIII в.: «Архитектор начинает создавать уединенные места, чтобы обеспечить автономию обитателей жилища и одновременно некоторую форму общения, которую можно назвать “выбранной” - в противовес бытовавшему до сих пор “навязанному” общению» [І8]. Очевидно и то, что в романах будуары, ложи, укромные уголки и др. несут символическое значение, являясь не только условием, но и выражением телесной близости; они могут быть даже истолкованы как аллегория тела.

Кажется, что такого рода наблюдения исчерпывающе описывают художественное пространство романов эпохи Просвещения. В самом деле, если мы обратимся к пространственным понятиям в кребийоновских романах (по крайней мере, ранних - I730-х гг.: «Танзай и Неадарне», «Софа» и «Заблуждения сердца и ума»), мы обнаружим здесь следующие места действия. В первом романе - покои Неадарне, карета, храм, ложе, зал королевского дворца, салон, оперная ложа, несколько, так сказать, природных топосов - луг, усеянный цветами, полутемная роща, ковер из трав и цветов и т. п. $\mathrm{B}$ «Софе» - женская половина дворца Шах-Бахама, где происходят события рассказа, кабинет Фатимы, куда поместили софу с переселившейся в нее душой Аманзея (не случайно замечание - «софе не пристало стоять в прихо- 
жей»), а далее различные спальни, кабинеты тех дам, об истории которых рассказывает Аманзей. В «Заблуждениях» перед нами предстают гостиная мадам де Люрсе, в основном посещаемая де Мелькуром, Опера, в которой из ложи можно наблюдать за дамами, сидящими в зрительном зале, и сад, в котором выделены укромные уголки, позволяющие уединиться для интимной, доверительной беседы и т. п. Таким образом, у Кребийона, как и у других романистов рококо, запечатлен в произведениях характерный для поэтики данного направления процесс интерьеризации и интимизации пространства (см., например: [3о]).

Однако если обратиться не только к выявлению того, какие топосы становятся местом действия в рокайльных романах, но и к способу их описания, и к их функции, то очевидно, что сделанных наблюдений и выводов недостаточно. Единицы пространства изучены литературоведами явно более тщательно, чем внутрироманные пространственные отношения. Представляется, что изолированное изучение отдельных топосов, отсутствие анализа их соотношения, специфики восприятия персонажем фабульной топографии не дает возможности исследовать поэтику романного пространства того или иного романиста во всей полноте.

Это касается и названных произведений Кребийона. Заметим, что отчетливо различные и по жанровым определениям (японская сказка, моральная история, мемуары), и по заявленному географическому пространству (сказочно-экзотическому, ориентальному - в первых двух произведениях и знакомому, парижскому, - в «Заблуждениях») эти романы рисуют нам, в то же время, один мир и один жизненный маршрут, определяемый словом «égarement», которое можно перевести и как «заблуждение», и попросту как «блуждание»: перемещение героев не линейно, оно может быть описано с помощью глаголов «приближаться» и «удаляться», по существу, единственных, которые указывают на положение персонажей в пространстве. Причем, взгляды персонажей и автора всегда направлены горизонтально и никогда вверх или вниз.

Кроме того, это пространственное положение и перемещение персонажей в романах Кребийона дано очень скупо и абстрактно. Места действия лишь называются, но не изображаются. Впрочем, на эту особенность уже обращали внимание специалисты. Очень редкие обозначения пространства и места действия констатирует в романах Кребийона А. Лафон [20, с. 458]; 
«ничего не говорится о гостиницах, где останавливаются герои, о комнатах, в которых они живут...», - замечает Ж. Дажан [І4, с. 32]; о том, что хотя читателям «Заблуждений» ясно, что действие происходит в Париже, название города не всплывает в тексте вообще, а уж тем более нет описаний города, указывает М.-А. Зуаги-Кейм [33, с. 556-557].

Можно было бы, вслед за другими литературоведами увидеть здесь только предпочтение, которое Кребийон отдает не описаниям, а разговорам между персонажами, связать эту скупость топографических деталей с классицистичностью его стиля, кажется, чересчур прямолинейно подражающего стилю Ж. Расина. Однако представляется, что такое абстрактнолаконичное изображение пространственных отношений связано не с «повторением пройденного» классицизмом, а с новым рокайльным процессом психологической натурализации повествования, с тем, что писатель мыслит и запечатлевает пространство не утрированно архитектонически (подчеркнуто демонстрируя его структуру), что присуще барочному роману, а естественно-органически, с «обычной», психологически «реалистичной» долей фиксации пространственных деталей.

Вот почему даже в таком романе, как «Софа», где, казалось бы, следует ожидать пространственных подробностей, нет специфического угла зрения одушевленной софы (уточнения «уселась» или «уселся на меня» даны лишь дважды во всем тексте, но то, что описывает «софа», не предполагает взгляда снизу, и вообще не предполагает некоей топографической конкретности поз или жестов). Это очень условный, абстрактный вуайеризм, если принять популярное в работах о Кребийоне определение. Становится очевидно, что такую абстрактность не объяснить только риторической традицией, коль скоро эта традиция была гораздо сильнее в литературе предшествующего, XVII столетия, однако пространственная риторика и риторика жестов подробно воссоздавалась в романе барокко (см. в частности: [I5]).

Дело, кажется, в том, что как бы ни был игрив и сколь бы ни был игровым художественный мир рокайльной романистики, он предполагает иной тип нарративной игры, нежели в предшествующем романе барокко. Особенность барочной театральности предполагает зрелищность, буквальную зримость образа, некое переложение драматического действия в вербальное, что не характерно для «натурализованной» театральности рококо, заменяющей подчеркнуто театральную форму игрового житейской, так сказать, «дет- 
ской» игрой, переходящей со сцены за кулисы, где, по словам Ж. Вайсгербеpa, «не вполне жизнь, но и не вполне театр» [29, с. І3I]. Потому-то эпизоды романов Кребийона, по существу, не построены как мизансцены. Сравним, например, сцену свидания из «Астреи» де Юрфе и из «Танзаи и Неадарне». В одном случае мы сталкиваемся с подробным, можно сказать «сценарным», «расписыванием» топографии местности, поз и положения героев по отношению друг к другу и к пространству:

«Астрея приближалась довольно медленно; можно было заметить, что душу ее что-то томило, понуждая настолько погрузиться в свои мысли, что нечаянно, нет ли, пройдя рядом, она и глаз не повела в сторону пастуха и отправилась устраиваться довольно далеко на берегу. Селадон, не придав сему значения, полагая, что пастушка не заметила его и пошла на обычное место их встреч, собрал посохом овеи и погнал их к ней. Астрея уже уселась подле старого ствола, рукою опершись на колено, подперев голову ладонью, и была столь задумчива, что не будь Селадон чрезмерно слеп в своем несчастии, легко увидел бы, что только перемена сердечной привязанности и никакое другое огорчение не могло быть причиной горестных и глубоких сих раздумий» [І2, с. 75].

Иначе - в романе «Танзай и Неадарне», где мы имеем дело с расплывчато-неопределенным пространственным передвижением персонажей, с фиксацией не поз, а прежде всего их психологического состояния, чувственно-эмоционального переживания:

«Едва забрезжил рассвет того дня, который позволял Танзаю остаться наедине с принцессой, он, подгоняемый движениями сердиа, поспешил под ее окна, где и ожидал прекрасного мига свидания.

Неадарне, взволнованная не меньше его, тоже пробудилась раньше обычного. Первые звуки, донесшиеся до ее слуха, оказались пением влюбленного принца, импровизировавшего на тему своей страсти. Она вскочила, но из боязни показавшись в окне, нарушить приличия, приказала, не желая упускать ни одной минуты из тех, что она могла бы употребить для беседы с принцем, устроить в своих покоях как можно больше шума. Танзай справедливо счел, что она уже проснулась, и отправился к ее дверям» [3, с. I7]. 
Может показаться, что различие пролегает лишь между кребийоновской рокайльной детеатрализацией и барочной театральностью пространственных единиц. Однако театральная риторика поз и жестов, столь очевидная в романах барокко, не чужда и классицистической романной прозе XVII столетия. В «Принцессе Клевской» М.M. де Лафайет она также присутствует, например:

«Дофина сидела на постели и негромко разговаривала с принцессой Клевской, стоявшей перед ней. Принцесса заметила за полузадернутой занавесью господина де Немура спиной к столу, стоявшему у изголовья кровати, и увидела, как он, не поворачивая головы, ловко взял что-то со стола» [5, с. 255], или: «Полученный герцогом удар так его оглушил, что какое-то время он, свесив голову, опирался на тех, кто его поддерживал» [5, с. 258], или: «Тропинки шли к небольшому домику, на первом этаже которого помещались зала и две примыкавшие к ней комнаты; одна выходила в иветник, отделенный от леса лишь изгородью, а другая - в аллею парка. Он вошел внутрь и стал бы разглядывать красоту убранства, если б не заметил, ито по этой аллее идут прини, и принцесса Клевские в сопровождении многочисленной челяди» [5, с. 274].

С одной стороны, трудно согласиться с теми исследователями, которые полагают, что скупостью и даже попросту отсутствием пространственных описаний Кребийон отличается от других романистов его времени Прево или Мариво. Анализ текстов показывает, что не только образцовый писатель рококо Мариво дает нам примеры сходных особенностей романного пространства и пространственных отношений ${ }^{2}$, но и Прево, поэтика которого сильнее связана с барочной традицией и в то же время содержит в себе ранне -сентименталистские черты, в основном демонстрирует подобные же лаконизм и абстрактность. Описание печальной фигуры де Грийе в ожидании отправки Манон в Америку совсем не обладает топографическими подробностями описания печальной Астреи:

\footnotetext{
2 У Мариво мы встречаем в «Жизни Марианны» ту же интерьерность пространства и ту же топографическую абстрактность. Ср., например, как описывает Марианна свое пребывание на церковной службе: «... я пошла в церковь, у входа теснились прихожане, но я не осталась в их толпе... я постаралась пробраться в ту часть церкви, где заметила благородных особ...» и т. д. [7, с. 70]. При этом не указано, где находилась эта часть церкви, пошла ли героиня направо или налево, была ли церковь просторной или небольшой и т. п.
} 
«Я обернулся к тому углу комнаты, где сидел молодой человек. Казалось, он был погружен в глубокую задумчивость, мне никогда не приходилось видеть более живой картины скорби, одежда его была крайне проста, но человека хорошей семьи и воспитания отличишь с первого взгляда. Я подошел к нему; он поднялся мне навстречу, и я увидел в его глазах, в лице, во всех его движениях столько изящества и благородства, что почувствовал к нему искреннее расположение» [Іо, с. 3I].

С другой стороны, подобная «топографическая абстрактность» существенно отличает романы Кребийона не только от барочного или классицистического романа XVII в., но и от фривольно-эротической романистики его времени, где преобладает «порнографическая» наглядность и конкретность поз и жестов. «Либертинное пространство» [27, с. 80] действия у Кребийона и в «Заблуждениях», и даже в «Софе», при всей интимности и комфортности для наблюдения находящихся в нем предметов и объектов, странным образом далеко не реализует потенциальные возможности пикантного вуайеризма. Эротическое соблазнение у Кребийона в сравнении с дотошным описанием поз героев «Терезы-философа» особенно явно оказывается не пространственно-визуальным, а, как верно заметил М. Конде, «чисто вербальным» [I3, с. I73-I74], и притом игровым, амбигитивным, сотканным из намеков, которые могут быть различно истолкованы. В некотором смысле можно распространить и на кребийоновскую прозу идею «двойного регистра», которую Ж. Руссе выдвинул, анализируя прозу Мариво [25, с. 45], «наивность» взглядов, представлений героя-протагониста интерферирует со скептической опытностью героя-рассказчика. Но, кроме того, с точки зрения романной топографии такой двойной регистр рассказывания собственной любовной истории подчиняет повествование логике «естественного» изложения, когда припоминается главное, существенное, то, что связано с важными, имеющими значение человеческими отношениями, чувствами, настроением, а не детали внешней обстановки.

Таким образом, в романистике Кребийона идет процесс если не разрушения, то значительной трансформации риторических топосов как барокко, так и классицизма, и эта трансформация осуществляется путем той натурализации и психологизации романического, которые являются общими для всех крупных создателей европейского романа рококо. 


\section{Список литературы}

I Ивин И. Художественное пространство // Ивин И. Философский словарь. URL: https://www.psyoffice.ru/6-I87-hudozhestvenoe-prostranstvo.htm (дата обращения: I2.I2.20I6).

Каширина С.В. Роль художественного пространства в постижении литературного текста // Вестник Оренбургского государственного университета. 2006. № 9. C. $\mathrm{I} 8 \mathrm{O}-\mathrm{I} 85$.

3 Кребийон-сын. Шумовка, или Танзай и Неадарне. Софа. М.: Ладомир-Наука, 2006. $367 \mathrm{c.}$

Кубрякова Е.С. Язык пространства и пространство языка (к постановке проблемы) // Изв. АН. Серия литературы и языка. І996. Т. 56. № 3. С. 22-31.

Лафайет М.М. Принцесса Клевская // Лафайет М.М. Соч. М.: Наука, 2007. C. 215-3I4.

Лотман Ю.М. О метаязыке типологических описаний культуры // Лотман Ю.М. Избранные работы: в 3 т. Таллинн, І992. Т. г. С. 386-392.

7 Мариво П.К. Жизнь Марианны. М.: Худож. лит., І999. 554 с.

8 Пигарева Т.И. Хорхе Гильен. Поэтика времени и пространства: автореф. дис. ... канд. филол. наук. М., 2002. 28 с.

9 Пономарева Н.M. Художественное пространство в нарративной структуре «уездных» рассказов Е.И. Замятина // Художественный текст и текст в массовых коммуникациях. Материалы международной научной конференции. Смоленск, 2005. Ч. 2. С. 79-83.

Iо Прево А.-Ф. История кавалера де Грие и Манон Леско // Прево. Манон Леско. Шодерло де Лакло. Опасные связи. М.: Правда, І985. С. 27-І45. Синицкая А.В. К проблеме пространственности в литературе // Вестник Самарского госуниверситета. Литературоведение. 2004. № I. С. I23-I43. Юрфе О.д’. Астрея // Новые переводы. Хрестоматия в помощь студентам-филологам. М.: УРAO, 2005. С. 73-98.

I3 Condé $M$. Crébillon fils // Condé $\mathrm{M}$. La génèse sociale de l'individualisme romantique. P., I986. P. I73-I74.

I4 Dagen J. Introduction à la sophistique amoureuse dans «Les égarements du cœur et de l'esprit» de Crébillon fils. P.: Honoré Champion, I995. I72 p.

I5 Dandrey P. Espaces en littérature au XVII siècle // Etudes littéraires. 2002. Vol. 34. $\mathrm{N}$ I-2. P. 7-27.

I6 Denon V. Point de lendemain. P.: Gallimard, I995. P. 38-39.

I7 Espaces, objets du roman au XVIII siècle. P.: Sorbonne Nouvelle, 2009. 206 p.

I8 Higelin-Fusté A. Le boudoir dans la littérature ou l'architecture de l'intime // Equinoxes. A graduate journal of french and francophone studies. 2008. N II. URL: http:// www.brown.edu/Research/journal/Issue\%/Eqxı__Higelin-Fuste (дата обращения: I2.I2.20I6). 
I9 Jiménez Salcedo J. R. La mécanique du plaisir: les espaces privés et les machines dans quelques romans du XVIII siècle // El texto como encrucijada: estudios franceses y francofonos. Logrono. Univ. de la Rioja, Servicio de Publicationes, 2004. P. 278-282. Lafon H. Les décors et les choses dans les romans de Crébillon // Poétique. I973. № I6. P. $455^{-465}$.

2I Lafon $H$. Espaces romanesques du XVIII siècle. De Madame de Villedieu à Nodier. Paris, Presses universitaires de France, I997. 216 p.

22 Lence M.-A. Point de lendemain de Vivant Denon: Analyse de l'espace // Espacio y texto en la cultura francesa. Publicationes de la Universidad de Alicante. 2006. P. 97I-984.

23 Locus in fabula. La topique de l'espace dans les fictions françaises d'Ancien Régime. Etudes réunies et présentées par N. Ferrand. Louvain-Paris, 2004. 716 p.

24 Martin C. Espaces du féminin dans le roman français du dix-huitième siècle. Oxford: SVEC, 2004. $527 \mathrm{p}$.

25 Rousset J. Marivaux ou la structure du double régistre // Rousset J. Forme et signification. Essai sur les structures littéraires de Corneille à Claudel. P.: Corti, I970. P. 45-64.

26 Songe, illusion, égarement dans les romans de Crébillon / Sous la dir. de J. Sgard. Grenoble, I996. 330 p.

27 Vàzquez L. Le Sopha et se conséquences. Succès d'une esthétique del'intimisme // Songe, illusion, égarement dans les romans de Crébillon / Sous la dir. de J. Sgard. Grenoble, I996. P. 93-IO4.

28 Weisgerber J. L'espace romanesque. Lausanne: L’Age d'homme, I982. 265 p.

29 Weisgerber J. Les masques fragiles: esthétique et formes de la littérature rococo. Lausanne, I991. 268 p.

30 Weisgerber J. Topographie du rococo: les cabinets de glaces // www: bon-à-tirer. com. Revue littéraire en ligne. N 88. I5 juillet 2008. URL: http: www.bon-a-tirer.com/ volume88/jw.html (дата обращения: І2.I2.20I6).

3I Ziemek A. L'espace mondaine dans l'écriture romanesque du XVIII siècle // Le siècle de Voltaire, hommage à René Pomeau. Oxford, The Voltaire Foundation, I987. P. 324-356.

32 Ziethen A. La littérature et l'espace // Arborescences: revue d'études françaises. 20I3. N 3. URL: http://id.erudit.org/iderudit/IOI7363ar (дата обращения: І2.I2.20I6).

33 Zouaghi-Keime M.-A. Lieux et codes dans le roman libertin. A propos des «Egarements du cœur et de l'esprit» de Crébillon / / Locus in fabula: la topique de l'espace dans les fictions françaises de I670-I820. P., I997. P. 556-557. 


\section{References}

I Ivin I. Khudozhestvennoe prostranstvo [Fictional space]. Ivin I. Filosofskiy slovar [Philosophic dictionary]. Available at: http://terme.ru/dictionary/ı87/word/ (accessed I2 December 20I6). (In Russ.)

Kashirina S.V. Rol khudozhestvennogo prostranstva v postizhenii literaturnogo teksta [The role of fictional space in our understanding of a literary work]. Vestnik Orenburgskogo gosudarstvennogo universiteta, 2006, no 9, pp. I80-I85. (In Russ.)

Krebiyon-syn. Shumovka, ili Tanzay i Neadarne [Crébillonfils. L'Écumoire ou Tanzaï et Néadarné]. Sofa [Le Sopha]. Moscow, Nauka Publ., 2006. 367 p.

Kubryakova E.S. Yazyk prostranstva i prostranstvo yazyka (k postanovke problemy) [The language of space and the space of the language]. Izv. AN. Seriya literatury i yazyka, I996, vol. 56, no 3, pp. 22-3I. (In Russ.)

Lafayet M.M. Princessa Klevskaya. Lafayet M.M. Sochineniya [Works] Moscow, LadomirNauka Publ., 2007, pp. 215-3I4.

6 Lotman Yu. M. O metayazyke tipologicheskikh opisaniy kultury [On the meta-language of typologic descriptions of culture]. Lotman Yu. M. Izbrannye raboty: $\mathrm{v} 3 \mathrm{t}$. [Selecter works: in 3 vols.]. Tallinn, I992, vol. I, pp. 386-392. (In Russ.)

7 Marivo P.K. Zhizn Marianny [Marivaux P. C. La vie de Marianne]. Moscow, Khud. lit. Publ., I999. 554 p.

8 Pigaryova T.I. Khorkhe Gilen. Poetika vremeni i prostranstva. Avtoref. dis ... kand. filol. nauk [Jorge Gilen. Poetics of time and space. Diss. Thesis]. Moscow, 2002. 28 p. (In Russ.)

9 Ponomareva N. M. Khudozhestvennoe prostranstvo v narrativnoy strukture "uezdnykh” rasskazov E.I. Zamyatina [Fictional space in the narrative structure of Zamyatin's tales]. Khudozhestvennyy tekst i tekst v massovykh kommunikaciyakh. Materialy mezhdunarodnoy nauchnoy konferencii [Fictional text and text in mass communications. Collection of conference papers]. Smolensk, 2005, part 2, pp. 79-83. (In Russ.) Prevo A.-F. Istoriya kavalera de Grie i Manon Lesko [Histoire du chevalier des Grieux et de Manon Lescaut]. Prevo. Manon Lesko. Shoderlo de Laklo. Opasnye svyazi [Manon Lescaut. Choderlos de Laclos. Les Liaisons dangereuses]. Moscow, Pravda Publ., I985, pp. 27-I45.

II Siniczkaya A.V. K probleme prostranstvennosti v literature [On the problem of space in literature]. Vestnik Samarskogo gosuniversiteta. Literaturovedenie, 2004, no I, pp. I23-I43. (In Russ.)

I2 Urfe O. d'. Astreya [Honoré de Urfé. L’Astrée]. Novye perevody. Khrestomatiya v pomoshch studentam-filologam [New translations. Reader for students of philology]. Moscow, URAO Publ., 2005, pp. 73-98. (In Russ.)

I3 Condé M. Crébillon fils. Condé M. La génèse sociale de l'individualisme romantique. Paris, I986, pp. I73-I74. (In French)

I4 Dagen J. Introduction à la sophistique amoureuse dans «Les égarements du cœur et de l'esprit» de Crébillon fils. Paris, Honoré Champion, I995. I72 p. (In French) 
I5 Dandrey P. Espaces en littérature au XVII siècle. Etudes littéraires, 2002, vol. 34, N I-2, pp. 7-27. (In French)

I6 Denon V. Point de lendemain. Paris, Gallimard, I995, pp. 38-39. (In French)

I7 Espaces, objets du roman au XVIII siècle. Paris, Sorbonne Nouvelle, 2009. 206 p. (In French)

I8 Higelin-Fusté A. Le boudoir dans la littérature ou l'architecture de l'intime. Equinoxes. A graduate journal of french and francophone studies. 2008. N II. Available at: http://www.brown.edu/Research/journal/Issue\%/EqxiI_Higelin-Fuste (accessed I2 December 20I6). (In French)

I9 Jiménez Salcedo J. R. La mécanique du plaisir: les espaces privés et les machines dans quelques romans du XVIII siècle. El texto como encrucijada: estudios franceses y francofonos. Logrono. Univ. de la Rioja, Servicio de Publicationes, 2004, pp. 278-282. (In French)

20 Lafon H. Les décors et les choses dans les romans de Crébillon. Poétique, I973, № 6, pp. 455-465. (In French)

2I Lafon H. Espaces romanesques du XVIII siècle. De Madame de Villedieu à Nodier. Paris, Presses universitaires de France, I997. 216 p. (In French)

22 Lence M.-A. Point de lendemain de Vivant Denon: Analyse de l'espace. Espacio y texto en la cultura francesa. Publicationes de la Universidad de Alicante, 2006, pp. 97I-984. (In French)

23 Locus in fabula. La topique de l'espace dans les fictions françaises d'Ancien Régime. Etudes réunies et présentées par N. Ferrand. Louvain-Paris, 2004.716 p. (In French)

24 Martin C. Espaces du féminin dans le roman français du dix-huitième siècle. Oxford, SVEC, 2004. 527 p. (In French)

25 Rousset J. Marivaux ou la structure du double régistre. Rousset J. Forme et signification. Essai sur les structures littéraires de Corneille à Claudel. Paris, Corti, I970, pp. 45-64. (In French)

26 Songe, illusion, égarement dans les romans de Crébillon. Sous la dir. de J. Sgard. Grenoble, I996. 330 p. (In French)

27 Vàzquez L. Le Sopha et se conséquences. Succès d'une esthétique del'intimisme. Songe, illusion, égarement dans les romans de Crébillon. Sous la dir. de J. Sgard. Grenoble, I996, pp. 93-IO4. (In French)

28 Weisgerber J. L'espace romanesque. Lausanne, L'Age d'homme, I982. 265 p. (In French)

29 Weisgerber J. Les masques fragiles: esthétique et formes de la littérature rococo. Lausanne, I99I. 268 p. (In French)

30 Weisgerber J. Topographie du rococo: les cabinets de glaces. www: bon-à-tirer.com. Revue littéraire en ligne. N 88. I5 juillet 2008. Available at: http: www.bon-a-tirer.com/ volume88/jw.html (accessed I2 December 20I6). (In French) 
3I Ziemek A. L'espace mondaine dans l'écriture romanesque du XVIII siècle. Le siècle de Voltaire, hommage à René Pomeau. Oxford, The Voltaire Foundation, I987, pp. 324-356. (In French)

32 Ziethen A. La littérature et l'espace. Arborescences: revue d'études françaises. 20I3. N 3. Available at: http://id.erudit.org/iderudit/Ior7363ar (accessed I2 December 20I6). (In French)

33 Zouaghi-Keime M.-A. Lieux et codes dans le roman libertin. A propos des «Egarements du cœur et de l'esprit» de Crébillon. Locus in fabula: la topique de l'espace dans les fictions françaises de I670-I820. Paris, I997, pp. 556-557. (In French) 